\title{
Size-segregated aerosol mass closure and chemical composition in Monte Cimone (I) during MINATROC
}

\author{
J.-P. Putaud ${ }^{1}$, R. Van Dingenen ${ }^{1}$, A. Dell'Acqua ${ }^{1}$, F. Raes ${ }^{1}$, E.Matta ${ }^{2}$, S. Decesari ${ }^{2}$, M.C. Facchini ${ }^{2}$, and S. Fuzzi ${ }^{2}$ \\ ${ }^{1}$ European Commission, Joint Research Centre, Institute for Environment and Sustainability, Ispra (Va), Italy \\ ${ }^{2}$ Consiglio Nazionale delle Ricerche, Istituto delle Scienze dell' Atmosfera e del Clima, Bologna, Italy
}

Received: 16 April 2003 - Published in Atmos. Chem. Phys. Discuss.: 29 July 2003

Revised: 13 February 2004 - Accepted: 21 May 2004 - Published: 21 June 2004

\begin{abstract}
Physical and chemical characterizations of the atmospheric aerosol were carried out at Mt. Cimone (Italy) during the 4 June-4 July 2000 period. Particle size distributions in the size range $6 \mathrm{~nm}-10 \mu \mathrm{m}$ were measured with a differential mobility analyzer (DMA) and an optical particle counter (OPC). Size-segregated aerosol was sampled using a 6-stage low pressure impactor. Aerosol samples were submitted to gravimetric and chemical analyses. Ionic, carbonaceous and refractory components of the aerosol were quantified. We compared the sub- and super- $\mu \mathrm{m}$ aerosol mass concentrations determined by gravimetric measurements $\left(\mathrm{m}_{G M}\right)$, chemical analyses $\left(\mathrm{m}_{C A}\right)$, and by converting particle size distribution to aerosol mass concentrations $\left(\mathrm{m}_{S D}\right)$. Mean random uncertainties associated with the determination of $\mathrm{m}_{G M}, \mathrm{~m}_{C A}$, and $\mathrm{m}_{S D}$ were assessed. The three estimates of the sub- $\mu \mathrm{m}$ aerosol mass concentration agreed, which shows that within experimental uncertainty, the sub- $\mu \mathrm{m}$ aerosol was composed of the quantified components. The three estimates of the super- $\mu \mathrm{m}$ aerosol mass concentration did not agree, which indicates that random uncertainties and/or possible systematic errors in aerosol sampling, sizing or analyses were not adequately accounted for. Aerosol chemical composition in air masses from different origins showed differences, which were significant in regard to experimental uncertainties. During the Saharan dust advection period, coarse dust and fine anthropogenic particles were externally mixed. No anthropogenic sulfate could be found in the super- $\mu \mathrm{m}$ dust particles. In contrast, nitrate was shifted towards the aerosol super- $\mu \mathrm{m}$ fraction in presence of desert dust.
\end{abstract}

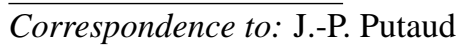

(jean.putaud@jrc.it)

\section{Introduction}

Due to the short atmospheric lifetime and complex chemical composition of atmospheric aerosols, their global distribution shows large regional differences and their radiative properties are poorly known. As a consequence, the radiative forcing by aerosols is the most uncertain, the most heterogeneous, and susceptible to the fastest changes (IPCC, 2001). Very little is still known about the aerosol forcing related to the effect of particles on the size and number of cloud droplets. Not even best estimates of the current forcing by mineral dust can be given (IPCC, 2001). The parameters controlling the aerosol direct and indirect radiative forcing can be calculated from the aerosol composition as a function of the particle size. Ideally, single particle size, composition, (and shape) should be determined. Recently developed instruments based on aerodynamic sizing and time of flight mass spectroscopy are able to size and analyze on-line particles ranging in size from a few tens of $\mathrm{nm}$ to a few $\mu \mathrm{m}$ (e.g. Carson et al., 1997; Ge et al., 1998). However, obtaining quantitative measurements is still challenging (Murphy et al., 1998). An alternative is to measure simultaneously but independently the aerosol size distribution, chemical composition and mixing state. The consistency of the various needed complementary analytical techniques can be evaluated by closure experiments.

This work focuses on the size-segregated aerosol chemical composition observed during the first MINATROC (MINeral dust And TROpospheric Chemistry) field experiment at Mte Cimone, Italy (2165 ma.s.l.). We investigate how well the aerosol mass can be described as a mixture of the measured organic and inorganic aerosol components in the sub- and super- $\mu \mathrm{m}$ aerosol fractions. For this, we compare the aerosol size-segregated mass concentration determined from gravimetric measurements $\left(\mathrm{m}_{G M}\right)$ with the aerosol volume calculated particle size distribution measurements, from which we derive the aerosol mass estimate $\mathrm{m}_{S D}$. The aerosol 
size-segregated mass concentration determined from chemical analyses $\left(\mathrm{m}_{C A}\right)$ is compared to $\mathrm{m}_{G M}$ and $\mathrm{m}_{S D}$. The uncertainties associated with each of the methods are quantified, and the differences between these independent estimates compared to these uncertainties.

This mass closure experiment allows us to determine whether in various synoptic situations the aerosol chemical composition changed significantly with regard to the uncertainties. In particular, we describe the changes in aerosol anthropogenic components' size distribution in a long-range transported desert dust plume.

\section{Experimental set-up}

\subsection{Site and meteorology}

The measurements were made between 4 June and 4 July 2000 at the CNR Monte Cimone station (MTC, $44^{\circ} 11^{\prime} \mathrm{N}-$ $10^{\circ} 42^{\prime} \mathrm{E}, 2165 \mathrm{~m}$ a.s.l.). MTC is located on the highest summit of the Northern Apennines, and experiences long range transport of air masses from Europe, the Mediterranean basin, and Africa, with on average 5 major dust outbreaks per year (Bonasoni et al., 1996). Ancillary measurements include meteorology, $\mathrm{CO}_{2}$ and $\mathrm{O}_{3}$ (Bonasoni et al., 1996, 2000). During the experiment, hourly mean temperature, wind speed and relative humidity averaged $9.5^{\circ} \mathrm{C}$ (range $4-18^{\circ} \mathrm{C}$ ), $5.6 \mathrm{~m} \mathrm{~s}^{-1}$ (range $1-20 \mathrm{~m} \mathrm{~s}^{-1}$ ), and $74 \%$ (range 1-100\%), respectively. Numerous parameters such as relative humidity, $\mathrm{CO}_{2}$ concentration and standard deviation, aerosol absorption coefficient $\left(\mathrm{B}_{a b s}\right)$ indicate that during the Minatroc campaign, MTC was reached from about 8:00 to 21:00 UTC by air masses coming from low altitude and therefore possibly affected by local pollution. For instance, average $\mathrm{CO}_{2}$ concentration dropped while $\mathrm{CO}_{2}$ standard deviation increased during daytime (Fig. 1), indicating that MTC was reached by air masses subjected to the vegetation $\mathrm{CO}_{2}$ sink. This is due to the summertime development of surface thermal winds causing up-slope flows that transport low altitude air to MTC.

\subsection{Aerosol mass concentration and chemical composition}

\subsubsection{Sampling}

Aerosol was sampled from the terrace of the MTC station situated about $3 \mathrm{~m}$ above ground. Size-segregated aerosol was collected at ambient relative humidity over 11-hour periods (10:00-21:00, and 22:00-09:00 UTC) using a lowpressure 6-stage Berner impactor (LPI 80/0.05) loaded with half foils of aluminum and half foils of Tedlar ${ }^{\mathrm{TM}}$. At the nominal flow rate of $80 \mathrm{~L} / \mathrm{min}$, the $50 \%$ aerodynamic cutoff diameters of this impactor are $0.05,0.14,0.42,1.20$, 3.46 and $10 \mu \mathrm{m}$ for stages 1 to 6 , respectively. To accumulate more material, aerosol was also collected through PM10 inlets on a $12 \mathrm{~h}$ basis with a high-volume sampler (Hi-Vol,
$500 \mathrm{~L} / \mathrm{min}$ ) and for several days or night using a virtual impactor built at the Joint research Centre (JRC) based on Loo and Cork's (1988) design. At the flow rate of $20.0 \mathrm{~L} / \mathrm{min}$ used during this experiment, the virtual impactor's $50 \%$ cutoff is $1.50 \pm 0.1 \mu \mathrm{m}$ aerodynamic diameter. The Hi-Vol sampler was loaded with ashless cellulose filters (Whatman 41). The virtual impactor sampled on pre-fired quartz fiber filters (Schleicher \& Schuell QF20).

\subsubsection{Analyses}

Low-pressure impactor stages $1-5$ were analyzed. The half foils of aluminum were used for gravimetric measurements of samples collected during the 17/06-04/07 period and for the analysis of organic carbon (OC) and black carbon (BC) in samples collected over the whole campaign period. They were weighed with a micro-balance (Sartorius, MC5) at $\mathrm{RH}=23 \pm 3 \%$ and $\mathrm{T}=24 \pm 1^{\circ} \mathrm{C}$ (Putaud et al., 2000). The mass of carbon collected on the aluminum foils was determined using a thermal method (Evolved Gas Analysis, EGA), where samples are exposed successively to 5 increasing temperature plateaus up to $650^{\circ} \mathrm{C}$ in an oxygen-free carrier gas, and then in an oxygen-rich carrier gas at $650-750^{\circ} \mathrm{C}$ (Putaud et al., 2000). The carbon evolved at $\mathrm{T}<650^{\circ} \mathrm{C}$ in $\mathrm{He}$ is defined as OC but contains also carbonate, and the fraction evolved at $\mathrm{T}>650^{\circ} \mathrm{C}$ in the oxidizing carrier gas is expected to be black carbon (BC). It appeared that the phenomenon of charring was particularly acute when analyzing samples collected on aluminum foils. The amplitude of the charring effect was assessed over 20 samples collected with the same Berner impactor at the same place at MTC in August 2001. Each sample was divided into two half foils, one of which was exposed at $340^{\circ} \mathrm{C}$ for $2 \mathrm{~h}$ in an oxidizing carrier gas ( $\mathrm{He}: \mathrm{O}_{2}$ 80:20). This thermal treatment was shown to remove most of the OC susceptible to be charred (Cachier et al., 1989). Both half foils were then analyzed using our routine method. BC was determined from the treated aliquot, and the difference in OC between the treated and not treated aliquot was interpreted as charred OC. The regression between the $\mathrm{BC}$ mass $(\mu \mathrm{g})$ found on the treated half foil vs. the $\mathrm{BC}$ mass found on the non-treated half foil $\left(\mathrm{BC}_{\text {treated }}=0.60\right.$ $\mathrm{BC}_{\text {non-treated }}, \mathrm{R}^{2}=0.97, \mathrm{n}=20$ ) was used to correct the $\mathrm{BC}$ data obtained from the non-treated samples collected during the Minatroc campaign.

Tedlar half foils were extracted in $6 \mathrm{~mL}$ of ultra-pure water (Millipore Organex system) and analyzed by ion chromatography (Dionex 500) for $\mathrm{Na}^{+}, \mathrm{NH}_{4}^{+}, \mathrm{K}^{+}, \mathrm{Mg}^{2+}, \mathrm{Ca}^{2+}$, acetate, formate, methanesulfonate (MSA), pyruvate, $\mathrm{Cl}^{-}$, $\mathrm{NO}_{2}^{-}, \mathrm{NO}_{3}^{-}, \mathrm{SO}_{4}^{2-}$, oxalate and for total water-soluble organic carbon (WSOC) with a Shimadzu TOC-5000A analyzer.

Four quartz filters collected with the virtual impactor were extracted in $6 \mathrm{ml}$ of ultrapure water. The extracts were concentrated to dryness and recovered with $1 \mathrm{ml}$ of deuterated water for HNMR analysis. Spectra were recorded at 


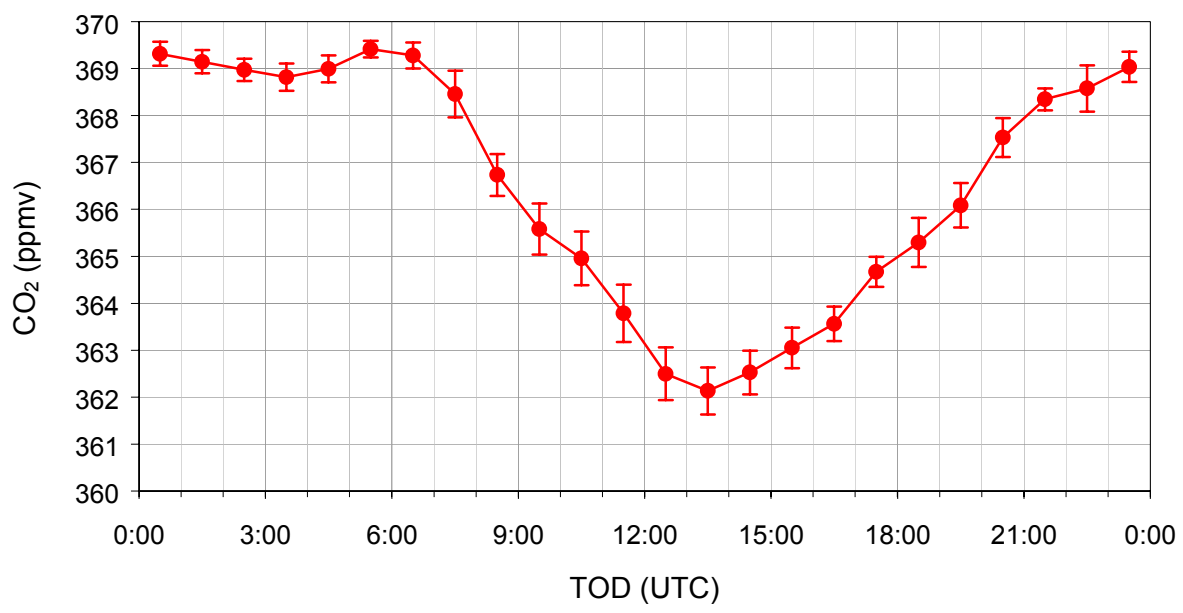

Fig. 1. Mean diurnal variations in $\mathrm{CO}_{2}$ concentrations at MTC during the 4 June-4 July 2002 period.

$400 \mathrm{MHz}$ in a $5 \mathrm{~mm}$ probe, with a Varian Mercury $400 \mathrm{spec}-$ trometer. A pre-saturation pulse sequence was adopted for suppression of the HDO signal (Decesari et al., 2000).

Cellulose filters collected with the Hi-Vol sampler were used for mineral dust quantification. Aliquots of filters were ashed at $600^{\circ} \mathrm{C}$ for $8 \mathrm{~h}$ in quartz crucibles after extraction of water soluble species in $\mathrm{mQ}^{\mathrm{TM}}$ water. The residue, defined as mineral dust, was weighed using a microbalance (Sartorius, MC5). Amounts of mineral dust significantly higher than the blank level $\left(1.0 \pm 0.8 \mu \mathrm{g} / \mathrm{cm}^{2}\right)$ were observed in $90 \%$ of the analyzed samples.

\subsubsection{Definition of the aerosol components.}

Except for $\mathrm{NH}_{4}^{+}, \mathrm{NO}_{3}^{-}$and $\mathrm{BC}$ concentrations, which were directly obtained from measurements, the main aerosol components were defined as a combination of the analyzed species. The regressions between $\mathrm{K}^{+}, \mathrm{Mg}^{2+}, \mathrm{Ca}^{2+}$ and $\mathrm{SO}_{4}^{2-}$ on one side and $\mathrm{Na}^{+}$on the other side indicate a common source for $\mathrm{Na}^{+}$and $\mathrm{Mg}^{2+}$ at MTC (sea spray) but not for $\mathrm{K}^{+}, \mathrm{Ca}^{2+}$ and $\mathrm{SO}_{4}^{2-}$. The sea salt fractions of $\mathrm{K}^{+}$, $\mathrm{Ca}^{2+}$ and $\mathrm{SO}_{4}^{2-}$ were calculated from the measured $\mathrm{Na}^{+}$ concentrations and a standard sea water composition. They were added to the sum of $\mathrm{Na}^{+}, \mathrm{Mg}^{2+}, \mathrm{Cl}^{-}$to calculate the sea salt component. $\mathrm{Cl}^{-}$was not calculated from $\mathrm{Na}^{+}$to account for possible losses of $\mathrm{Cl}^{-}$with respect to sea salt due to the reaction with acidic species. The sea salt fractions of $\mathrm{K}^{+}, \mathrm{Ca}^{2+}$ and $\mathrm{SO}_{4}^{2-}$ were subtracted to the measured concentrations of $\mathrm{K}^{+}, \mathrm{Ca}^{2+}$ and $\mathrm{SO}_{4}^{2-}$, respectively, to get the non-sea salt fraction of these species $\left(\mathrm{nssK}^{+}, \mathrm{nssCa}^{2+}\right.$ and $\mathrm{nsSSO}_{4}^{2-}$ ). The dust component was obtained from the regressions between $\mathrm{nsSCa}^{2+}$ and ash found in the $\mathrm{Hi}-\mathrm{Vol}$ samples. Different correlations were observed between $\mathrm{nssCa}^{2+}$ and mineral dust for periods with and without mineral dust (Fig. 2). The equations of the regressions:

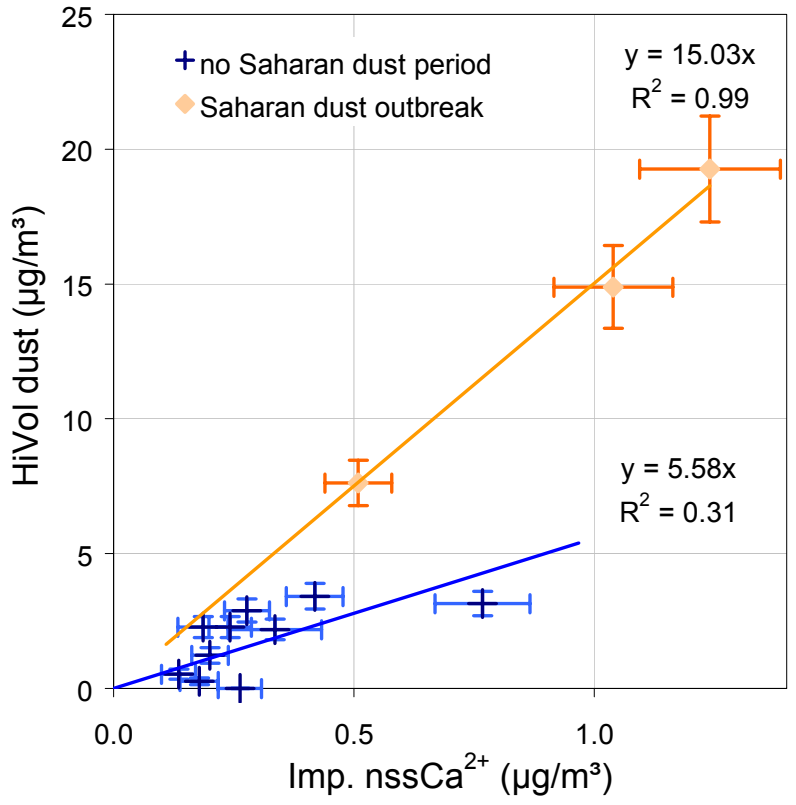

Fig. 2. Correlation between ash (considered to be mineral dust) and nss $\mathrm{Ca}^{2+}$ in samples collected with a PM10 Hi-Vol sampler and the cascade impactor, respectively. The regression observed out and during the desert dust advection period are shown.

mineral dust $=5.6 \times n s s \mathrm{Ca}^{2+}$, for non Saharan dust periods (1a)

mineral dust $=15.0 \times n s s \mathrm{Ca}^{2+}$, for the Saharan dust period (1b)

were used to estimate the amount of mineral dust in each stage of the impactor for each period, based on the amounts of $\mathrm{nssCa}^{2+}$. The regression between $\mathrm{nssCa}^{2+}$ and mineral dust was poorly significant out of the Saharan dust period, 
which was taken into account through the large uncertainty of the regression slope (see next section). Water soluble organic matter (WSOM) was derived from measured WSOC using a mean molecular-to-carbon mass ratio equal to 1.9 , corresponding to the raw molecular formulas for WSOM derived by HNMR functional group analysis (Fuzzi et al., 2001). Non-water soluble organic matter (NWSOM) was estimated as:

$N W S O M=1.2(O C-W S O C)$

The 1.2 molecular-to-carbon mass ratio is the lower limit reported for urban organic matter (Gray et al., 1986) and corresponds to large saturated hydrocarbons. For each sample, the "unknown" fraction was calculated as the difference between the aerosol mass $\mathrm{m}_{G M}$ or $\mathrm{m}_{S D}$ and the sum of the quantified aerosol components $\mathrm{m}_{C A}$.

\subsubsection{Uncertainties}

The weighing precision was $\pm 2 \mu \mathrm{g}$ and the standard variation of the aluminum blank foils $\pm 10 \mu \mathrm{g}(\mathrm{n}=5)$. The precision of $\mathrm{OC}$ and $\mathrm{BC}$ determination was $\pm 8 \%$. The uncertainty in the slope of the regression between the $\mathrm{BC}$ mass from the non-treated aliquots and the $\mathrm{BC}$ mass from the treated aliquots was \pm 0.03 (95\% confidence level). Blank variability for the OC and BC fraction were \pm 1.7 and $\pm 0.3 \mu \mathrm{g}$ foil ${ }^{-1}$, respectively $(n=15)$. Uncertainties in ion chromatography and WSOC measurements were estimated to $\pm 5 \%$. The precision of the water volume used to extract the samples was $\pm 0.04 \mathrm{~mL}$. Blank variability for $\mathrm{Na}^{+}, \mathrm{NH}_{4}^{+}, \mathrm{K}^{+}, \mathrm{Mg}^{2+}$, $\mathrm{Ca}^{2+}, \mathrm{Cl}^{-}, \mathrm{NO}_{3}^{-}, \mathrm{SO}_{4}^{2-}$, and WSOC were $\pm 48, \pm 12, \pm 17$, $\pm 3, \pm 23, \pm 30, \pm 70, \pm 28$, and $\pm 200 \mu \mathrm{g} \mathrm{L}^{-1}$, respectively $(n=25)$. The random uncertainty of the molecular massto-carbon mass ratios were arbitrary set to \pm 0.1 for both WSOM and NWSOM, because of the lack of data regarding the variability of these ratios. The uncertainty in the slope of the regression between ash and $\mathrm{nssCa}^{2+}$ masses measured from the Hi-Vol filters was \pm 2.1 for the 4 June-2 July period, and \pm 1.73 for the 3-4 July period ( $95 \%$ confidence level). Finally, based on measurements performed later with an identical impactor, the uncertainty in the sampling flow rate was estimated to $\pm 10 \%$. Tables 1 and 2 show how evolve the relative mean random uncertainties in each aerosol component and in the mass concentration estimates $\mathrm{m}_{C A}, \mathrm{~m}_{G M}$, and $\mathrm{m}_{S D}$, when sources of errors such analyses, blank variability, conversion from species to aerosol components, and air volume determination, are successively introduced. The law of propagation of errors (3) was used to combine absolute uncertainties associated with the determination of noncorrelated parameters. According to the law of propagation of errors, the random error $\mathrm{S}(\mathrm{y})$ of a variable $\mathrm{y}$ calculated as a function of $\mathrm{n}$ non-correlated parameters $\mathrm{x}_{i}, \mathrm{y}=\mathrm{f}\left(\mathrm{x}_{1}, \ldots, \mathrm{x}_{i}\right.$, $\left.\ldots, \mathrm{x}_{n}\right)$, can be approximated by:

$S^{2}(y)=\Sigma \partial f / d x_{i}\left(x_{1}, \ldots, x_{i}, \ldots, x_{n}\right) S\left(x_{i}\right)^{2}$ where $\left(\partial \mathrm{f} / \mathrm{d} x_{i}\right)$ represents the partial derivative of $f$ with respect to $\mathrm{x}_{i}$ and $\mathrm{S}\left(\mathrm{x}_{i}\right)$ is the absolute uncertainty of parameter $\mathrm{x}_{i}$. For correlated parameters, such as the various components of sea salt, absolute uncertainties were conservatively added. Uncertainties for the sub- $\mu \mathrm{m}$ aerosol range is also the sum of uncertainties for stages 1-3 of the impactor, and uncertainties for the super- $\mu \mathrm{m}$ range the sum of uncertainties for stages 4-5. The main source of uncertainty for the gravimetric method $\left(\mathrm{m}_{G M}\right)$ was the variability of the blank masses. For most aerosol components, the main source of random error is blank variability as well. Analytical precision is the largest source of random error only for $\mathrm{NH}_{4}^{+}, \mathrm{nssSO}_{4}^{2-}$, and $\mathrm{BC}$ in the aerosol sub- $\mu \mathrm{m}$ fraction, and for NWSOM in both the super- and sub- $\mu \mathrm{m}$ fraction. The large uncertainty in NWSOM derives from the fact that NWSOM was calculated as the difference between two quantities (2), which were for numerous samples much larger than NWSOM itself. The overall random uncertainty in the determination of the aerosol mass from chemical analysis $\left(\mathrm{m}_{C A}\right)$ was dominated by uncertainties in $\mathrm{OM}$ $(\mathrm{OM}=\mathrm{WSOM}+\mathrm{NSOM})$ and $\mathrm{nssSO}_{4}^{2-}$ for the sub- $\mu \mathrm{m}$ fraction, and by uncertainties in OM and dust for the super- $\mu \mathrm{m}$ fraction.

In addition to random uncertainties, systematic errors can occur, related to inaccurate sampling or analytical techniques. Aerosol sampling with low-pressure impactors is suspected to be affected by negative artifacts, due to the volatilization of semi-volatile particulate species. During Minatroc, sub- $\mu \mathrm{m}$ aerosol was collected and analyzed online at MTC using an artifact free sampler made of a wet annular denuder (WAD) combined with a steam jet aerosol collector (SJAC) built by ECN, Petten (Keuken et al., 1988; Khlystov et al., 1995). The correlation between the sub- $\mu \mathrm{m}$ $\mathrm{NO}_{3}^{-}$concentrations calculated from the impactor samples and the WAD-SJAC concentrations averaged over the impactor sampling time show that the low-pressure impactor did not lead to systematically lower concentrations than the artifact free sampler. This suggests that no significant loss of semi-volatile compounds occurred in the low-pressure impactor in the conditions encountered during this campaign. Possible losses of coarse dust particles into the impactor are discussed in Sect. 3.

The determination of OM concentrations is also affected by possibly large systematic errors due to the lack of accurate data regarding the molecular mass-to-carbon mass ratio of organic aerosol in NWSOM, and to the uncertainties involved by the assumptions needed to interpret HNMR data to determine the mean raw formula of WSOM. Such systematic uncertainties are very difficult to estimate. 


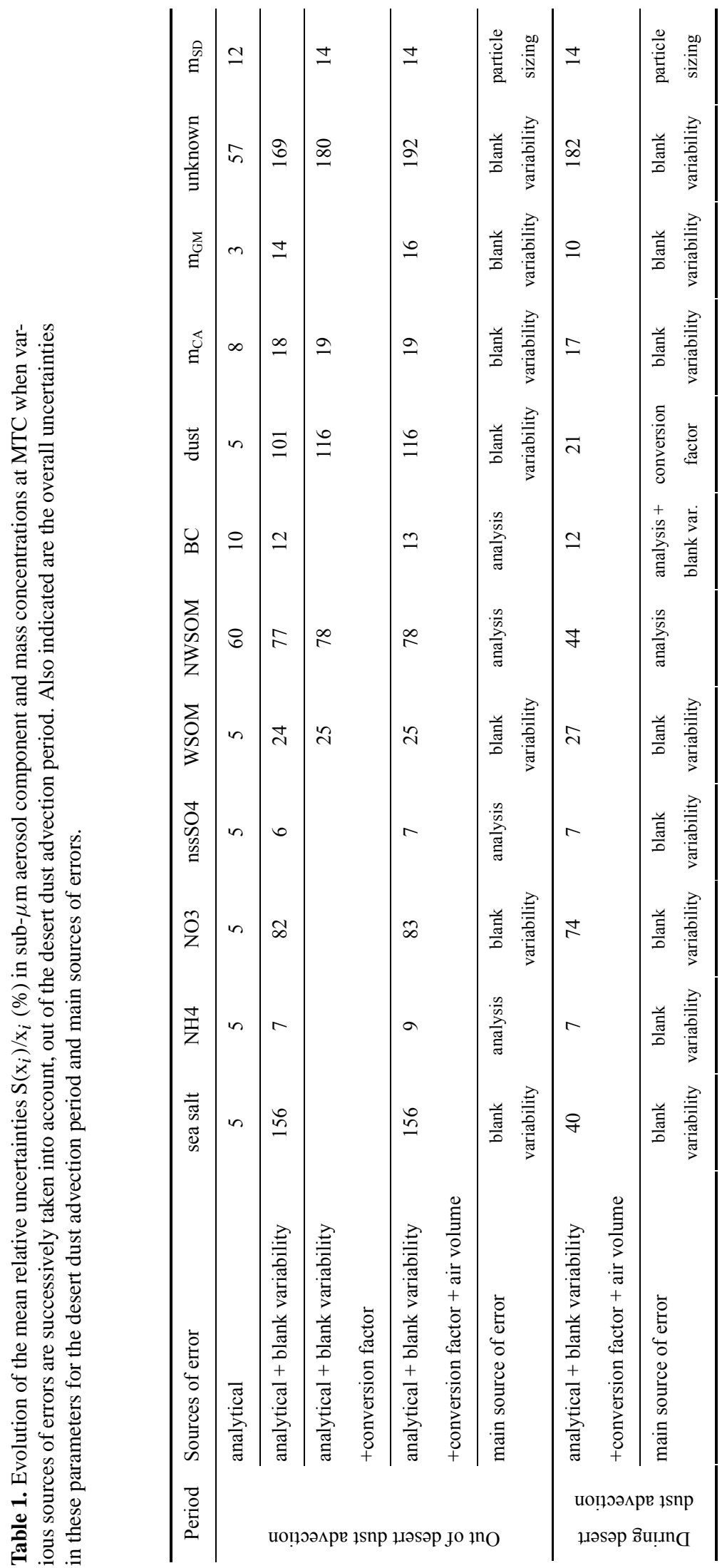




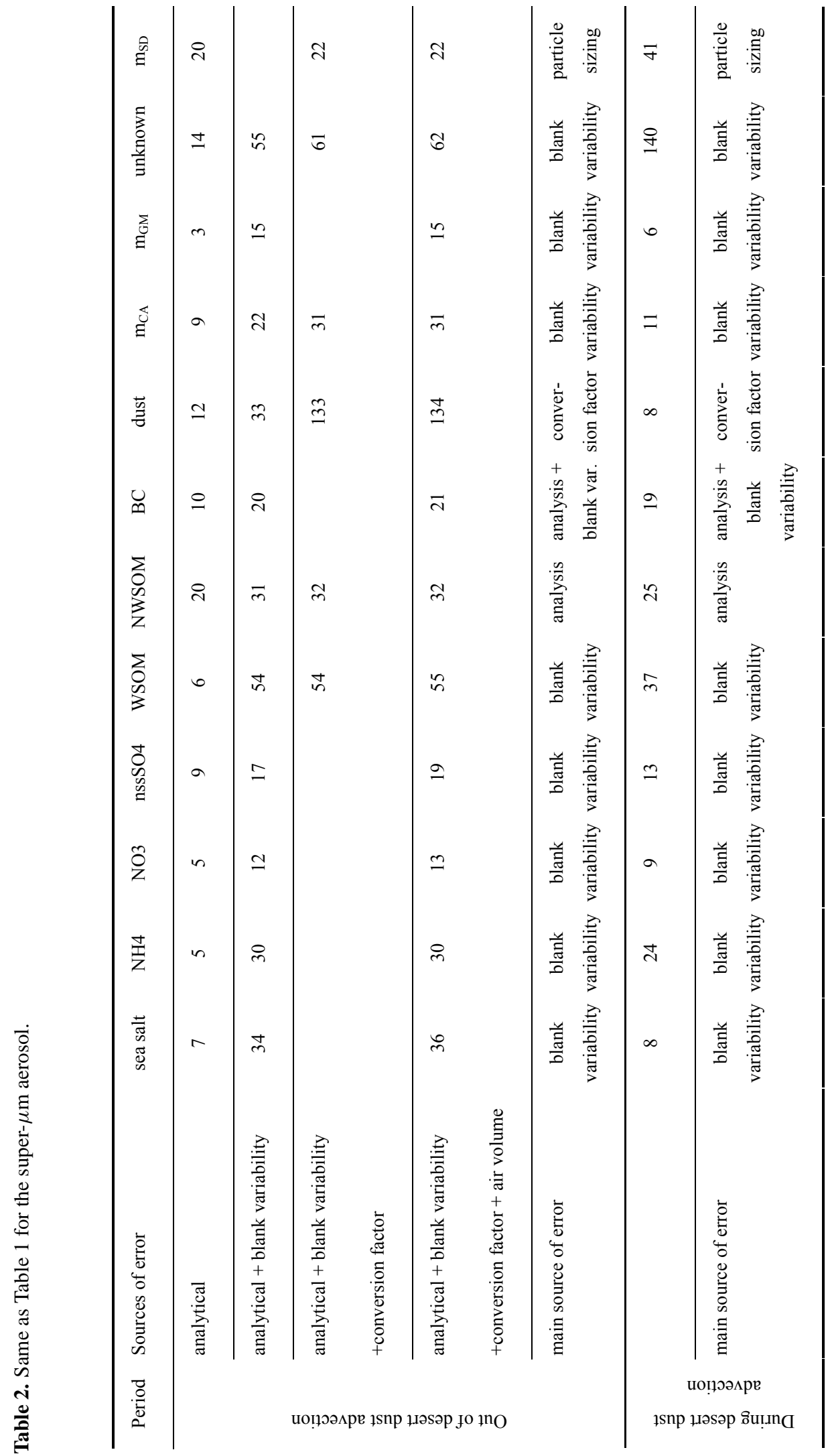




\subsection{Aerosol physical properties}

\subsubsection{Measurements}

All instruments sampled from the same PM10 inlet located at $4 \mathrm{~m}$ above the terrace floor. Particle size distributions at $5 \pm 5 \% \mathrm{RH}$ were measured with a 10 -min time resolution in the size range 6-600 $\mathrm{nm}$ using a Vienna type differential mobility analyzer (DMA). Particle size distributions for aerodynamic diameters greater than $0.3 \mu \mathrm{m}$ were measured using a Grimm 1.108 optical particle counter (OPC). The optical diameters determined by the OPC are converted to geometric diameters assuming spherical particles. A tandemDMA was used to measure the aerosol growth factor from 0 to $90 \% \mathrm{RH}$ at particle diameters of $10,20,50,100$ and $200 \mathrm{~nm}$. Aerosol absorption coefficient was measured with an Aethalometer ${ }^{\mathrm{TM}}($ Magee AE-1).

\subsubsection{Data processing}

Particle number size distributions measured with the DMA and the OPC agreed well in the overlapping 300-600 nm range (Van Dingenen et al., in preparation, $2004^{1}$ ). Volume size distributions were calculated assuming that aerosol particles were spheres with a diameter equal to that measured by the instruments. DMA rather than OPC data were considered in the $300-600 \mathrm{~nm}$ range, but this choice had no significant influence $(<1 \%)$ on the aerosol volume determination. Volume size distributions in the size range $6 \mathrm{~nm}-10 \mu \mathrm{m}$ were averaged over the impactor sampling periods.

\subsubsection{Uncertainties}

The possible error in DMA sizing due to the uncertainty in the air flow rates $( \pm 5 \%)$ are $-7,+5 \%$ of the particle diameter. The comparison with a condensation particle counter (CPC) indicates that the uncertainty in DMA counting was $\pm 2 \%$ (95\% confidence level). According to the manufacturer, the reproducibility of the Grimm 1.108 OPC in particle counting is $\pm 2 \%$. We assumed random uncertainties in particle sizing to $\pm 10 \%$ and $\pm 20 \%$ out and during the desert dust advection period, respectively. The overall random uncertainty in aerosol volume determination was controlled by the precision in particle sizing.

\footnotetext{
${ }^{1}$ Van Dingenen, R., Putaud, J. P., and Raes, F.: Physical aerosol properties and their relation to air mass origin at Monte Cimone (Italy) during the first MINATROC campaign, Atmos. Chem. Phys., in preparation, 2004.
}

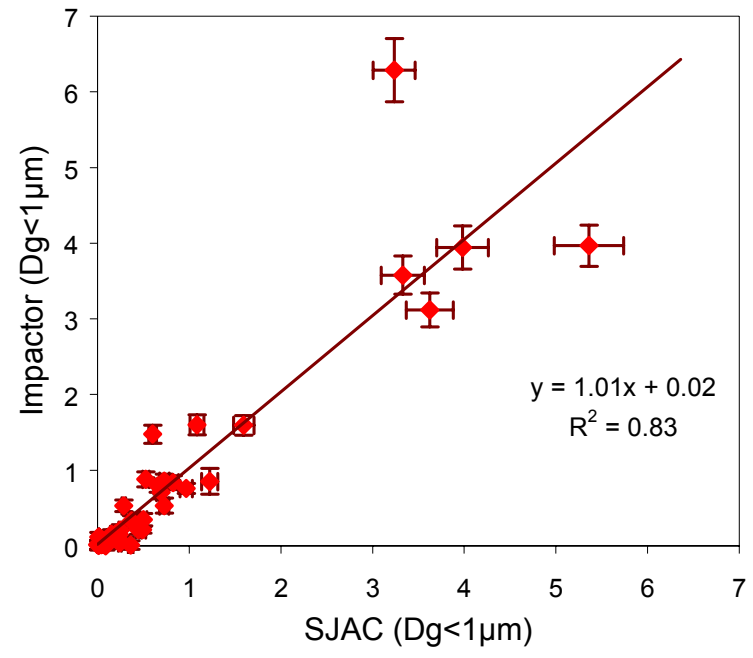

Fig. 3. Correlation between sub- $\mu \mathrm{m} \mathrm{NO}_{3}^{-}$concentrations obtained from stages $1-3$ of the low-pressure impactor and the artifact free WAD-SJAC combination.

\section{Results and discussion}

\subsection{Mass closure}

3.1.1 Comparison between the aerosol mass concentrations derived from gravimetric measurements and aerosol volume derived from particle size distributions.

Such a comparison requires first the conversion of the $50 \%$ aerodynamic cut-off diameters of the impactor operated at ambient temperature to geometric diameters measured in dry conditions in the particle sizing instruments. The aerodynamic diameter of a particle at ambient relative humidity $\mathrm{D}_{a}$ and its geometric diameter at $0 \%$ relative humidity $\mathrm{D}_{g}$ are linked by the relationship:

$D_{g}=1 / G F_{a} \times\left[D_{a} /\left(d_{a}\right)^{1 / 2}\right] \times\left[C c_{1} / C c_{d}\right]^{1 / 2}$

where $\mathrm{GF}_{a}$ and $\mathrm{d}_{a}$ are the particle growth factor and density at ambient relative humidity, and $\mathrm{Cc}_{1}$ and $\mathrm{Cc}_{d}$ are the slip correction factors for spheres with diameters $\mathrm{D}_{a}$ and $\mathrm{D}_{a} \times \mathrm{d}_{a}^{-1 / 2}$, respectively. Variations in the slip correction factors are significant for particle diameters $<0.2 \mu \mathrm{m}$ only. They were neglected in the conversion from aerodynamic to geometric cut-off diameters.

The aerosol density at ambient $\mathrm{RH}\left(\mathrm{d}_{a}\right)$ can be calculated by:

$d_{a}=\left(d_{0}+\left(G F_{a}^{3}-1\right) d_{w}\right) / G F_{a}^{3}$

where $\mathrm{d}_{0}$ is the aerosol density at $0 \%$ relative humidity, $\mathrm{d}_{w}$ is the density of water $(=1.0)$ and $\mathrm{GF}_{a}$ the aerosol growth factor at ambient relative humidity.

Aerosol growth factor at $90 \% \mathrm{RH}\left(\mathrm{GF}_{90}\right)$ were measured continuously at MTC during this campaign (Van Dingenen et 

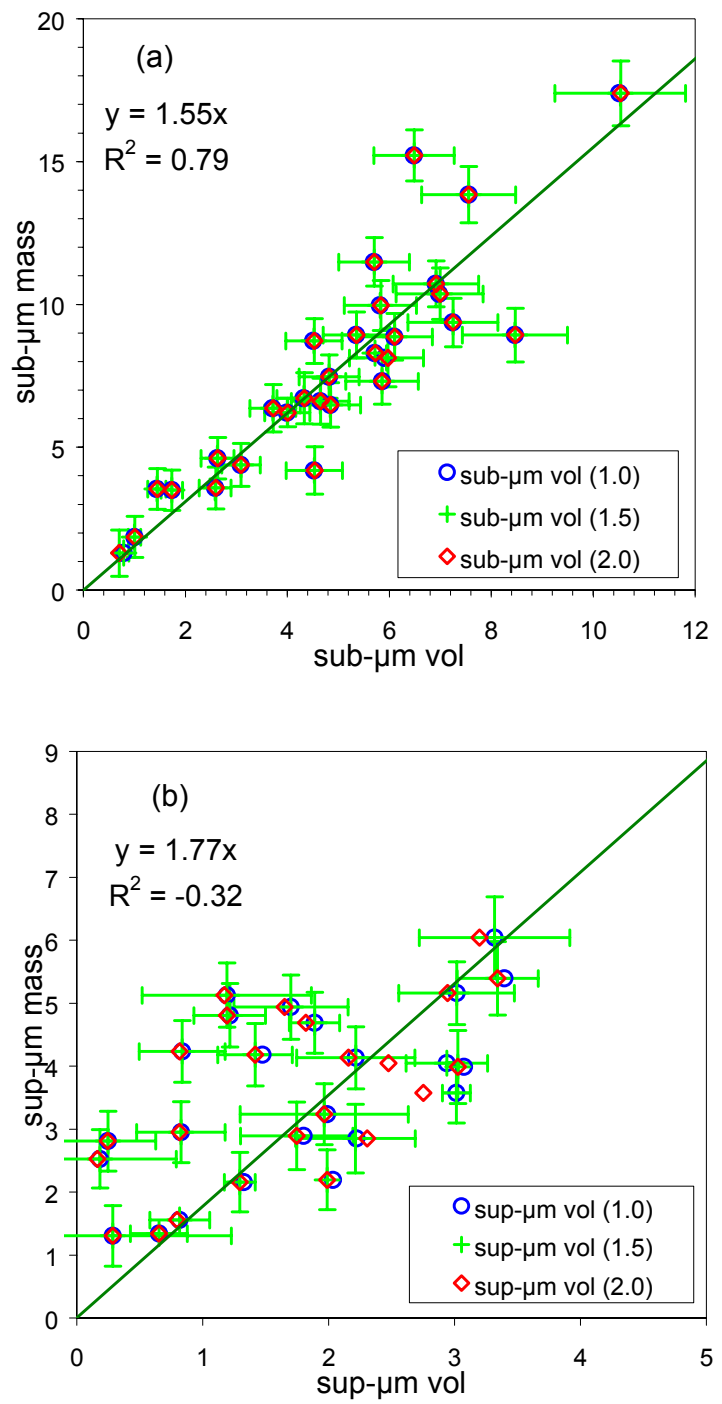

Fig. 4. Correlations between aerosol mass concentrations $\mathrm{m}_{G M}$ obtained from the low-pressure impactor and aerosol volume obtained from the DMA and OPC in (a) the sub- $\mu \mathrm{m}$ fraction and (b) the super- $\mu \mathrm{m}$ aerosol fraction out of the Saharan dust event. Data are shown for 3 values of the dry aerosol density $(1.0,1.5,2.0)$ considered a priori to convert aerodynamic to geometric diameters. The regression line corresponds to $\mathrm{d}=1.5$. Error bars indicate random uncertainties associated with $\mathrm{m}_{G M}$ and aerosol volume determinations.

al., in preparation, $2004^{2}$ ). From the $\mathrm{GF}_{90}$ values averaged over the impactor sampling periods, the fractions of hygroscopic $(\alpha)$ and hydrophobic $(1-\alpha)$ aerosol components were estimated assuming that (1) hygroscopic aerosol behave like $\left(\mathrm{NH}_{4}\right)_{2} \mathrm{SO}_{4}$, and (2) hydrophobic aerosol do not grow at any

\footnotetext{
${ }^{2}$ Van Dingenen, R., Putaud, J. P., and Raes, F.: Physical aerosol properties and their relation to air mass origin at Monte Cimone (Italy) during the first MINATROC campaign, Atmos. Chem. Phys., in preparation, 2004.
}
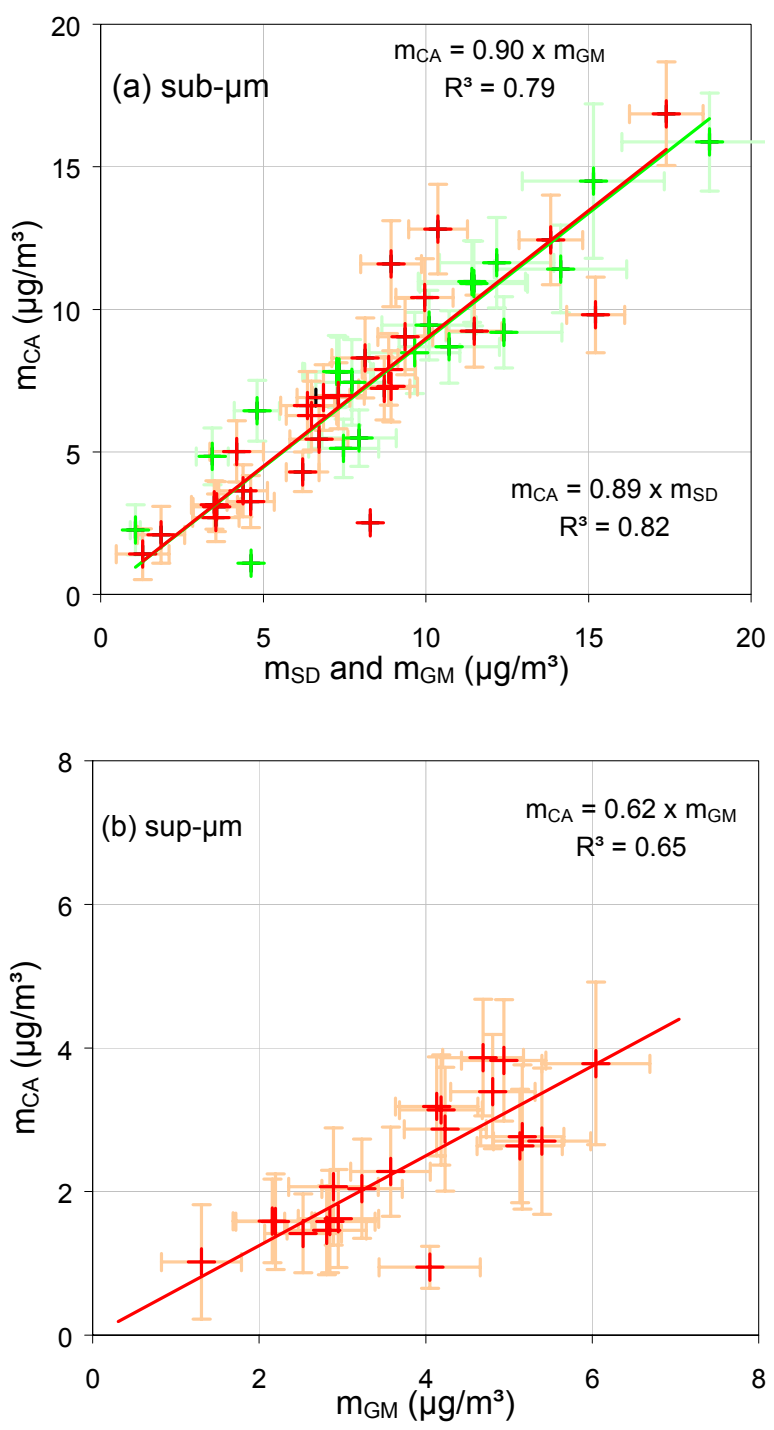

Fig. 5. Correlation between aerosol mass concentrations $\mathrm{m}_{G M}$ (red) and $\mathrm{m}_{C A}$ (green) obtained from the low-pressure impactor in (a) the sub- $\mu \mathrm{m}$ (b) the super- $\mu \mathrm{m}$ aerosol fractions out of the Saharan dust event. Error bars indicate random uncertainties associated with $\mathrm{m}_{G M}$ and $\mathrm{m}_{C A}$.

$\mathrm{RH}$, and the GF of a mixture can be calculated according to the formula (Virkkula et al., 1999):

$G F_{90}^{3}=\alpha G F_{90 \text { scopic }}^{3}+(1-\alpha) G F_{90 \text { phobic }}^{3}$

The coefficient $\alpha$ calculated from (6) was used to estimate the aerosol growth factor at ambient relative humidity, based on the above mentioned assumptions (1) and (2):

$$
G F_{a}^{3}=\alpha G F_{\text {a scopic }}^{3}+(1-\alpha) G F_{\text {a phobic }}^{3}
$$

For each impactor sample, the geometric diameter $\mathrm{D}_{g}(4)$ corresponding to the $50 \%$ cut-off diameter of stage $4(1.2 \mu \mathrm{m}$ aerodynamic diameter) was calculated for the dry aerosol 
Table 3. Magnitude of the relative differences and uncertainties in the relative difference between $\mathrm{m}_{C A}$, and $\mathrm{m}_{G M}$, in the sub- and super- $\mu \mathrm{m}$ aerosol fractions at MTC.

\begin{tabular}{lll}
\hline & Sub- $\mu \mathrm{m}$ & Super- $\mu \mathrm{m}$ \\
\hline $\begin{array}{l}\text { Relative difference } \delta\left(\mathrm{m}_{C A}, m_{G M}\right) \\
\text { between } \mathrm{m}_{C A} \text { and } \mathrm{m}_{G M}(\%)\end{array}$ & 17 & 37 \\
$\begin{array}{l}\text { Relative uncertainty } \sigma(\Delta) \text { of the difference } \\
\text { between } \mathrm{m}_{C A} \text { and } \mathrm{m}_{G M}(\%)\end{array}$ & 25 & 33 \\
\hline
\end{tabular}

density values 1.0, 1.5, 2.0 (this range of values largely covers the possible atmospheric dry aerosol density). This equivalent geometric diameter $\mathrm{D}_{g}(4)$ was found to be on average $0.95 \pm 0.12 \mu \mathrm{m}$. The aerosol mass concentration measured on stages 1-3 of the impactor was then compared to the aerosol volume integrated up to the geometric diameter $\mathrm{D}_{g}$ (4) (Fig. 4a), and the aerosol mass concentration measured on stages 4 and 5 of the impactor to the aerosol volume integrated from to the geometric diameter $\mathrm{D}_{g}(4)$ to $10 \mu \mathrm{m}$ (Fig. 4b). For the sub- $\mu \mathrm{m}$ aerosol range, a good correlation is observed between the gravimetrically measured mass $\mathrm{m}_{G M}$ and the aerosol volume, independently of the a priori assumed dry aerosol density. The slope of the regression suggests that the density of the dry aerosol was in the range $1.55 \pm 0.12$ (95\% confidence level) at MTC during the Minatroc campaign. For the periods when gravimetric measurements are not available, this regression together with the size distribution measurements performed on these days were use to estimate the sub- $\mu \mathrm{m}$ aerosol mass $\mathrm{m}_{S D}$. The comparison between gravimetrically measured mass and aerosol volume was carried out for each of the 3 sub- $\mu \mathrm{m}$ aerosol fractions resolved by the low-pressure impactor. A reasonable agreement could be found by assuming that the $50 \%$ cut-off diameter of stage 3 was 0.26 instead of the nominal $0.42 \mu \mathrm{m}$ value. Regarding the aerosol super- $\mu \mathrm{m}$ range, no correlation appears between the gravimetrically measured mass and the aerosol volume (Fig. 4b). The regression indicates that the discrepancies between super- $\mu \mathrm{m}$ aerosol mass and volume are not systematically due to losses of coarse particles into the impactor. It shows that coarse particle sampling with the low-pressure impactor and/or counting with the OPC were affected by random uncertainties (sampling artifacts into the impactor, error in particle sizing, etc.), which were not adequately accounted for.

3.1.2 Comparison between aerosol mass concentrations derived from gravimetric measurements and chemical analysis

Sub- and super- $\mu \mathrm{m}$ aerosol mass concentrations derived from gravimetric measurements $\left(\mathrm{m}_{G M}\right)$ and chemical analyses $\left(\mathrm{m}_{C A}\right)$ are compared in Fig. 5a and b, respectively. A good correlation appears for the sub- $\mu \mathrm{m}$ aerosol fraction (slope $=0.89, \mathrm{R}^{2}=0.82$ ), but not for the super $-\mu \mathrm{m}$ fraction (slope $=0.65, \mathrm{R}^{2}=0.58$ ). To compare $\mathrm{m}_{G M}$ and $\mathrm{m}_{C A}$ with regard to the uncertainty of each method, the absolute difference between two methods $\Delta=\left|\mathrm{m}_{C A}-\mathrm{m}_{G M}\right|$ was compared with the uncertainty in this difference $S(\Delta)$, which can be estimated according to Eq. (3) as:

$S(\Delta)^{2}=S\left(m_{C A}\right)^{2}+S\left(m_{G M}\right)^{2}$

Mean relative uncertainties $\sigma(\Delta)$ in the difference $\Delta$ and relative differences between the two methods $\delta\left(\mathrm{m}_{G M}, \mathrm{~m}_{C A}\right)$, respectively, defined by:

$\sigma(\Delta)=S(\Delta) / \mathrm{m}$

$\delta\left(\mathrm{m}_{G M}, \mathrm{~m}_{C A}\right)=(\Delta) / \mathrm{m}$

where $m=$ average $\left(\mathrm{m}_{G M}, \mathrm{~m}_{C A}\right)$, are listed in Table 3. For the sub- $\mu \mathrm{m}$ aerosol fraction, $\delta\left(\mathrm{m}_{G M}, \mathrm{~m}_{C A}\right)<\sigma(\Delta)$, which means that the difference between $\mathrm{m}_{G M}$ and $\mathrm{m}_{C A}$ are not statistically significant. This shows that the quantified aerosol components adequately describe the sub- $\mu \mathrm{m}$ aerosol mass. In contrast, for the super- $\mu \mathrm{m}$ fraction, $\delta\left(\mathrm{m}_{G M}, \mathrm{~m}_{C A}\right)>\sigma(\Delta)$, which indicates that differences in the aerosol mass determined from chemical analyses $\left(\mathrm{m}_{G M}\right)$ compared to gravimetry $\left(\mathrm{m}_{C A}\right)$ were larger than the estimated random errors. This suggests that systematic errors might not have been adequately taken into account.

\subsection{Aerosol chemical composition in various particle size classes and air masses}

During the Minatroc campaign, MTC was reached from about 8:00 to 21:00 UTC by air masses coming from low altitude and therefore possibly affected by local pollution (see 2.1). Impactor measurements show also that aerosol concentration was on average $30 \%$ higher during day-time compared to night-time, mainly due to enhanced mass concentrations in stages $2\left(0.14<\mathrm{D}_{a}<0.42 \mu \mathrm{m}\right)$ and $5\left(3.46<\mathrm{D}_{a}<10 \mu \mathrm{m}\right)$. However, the chemical composition in each size fraction did not vary much between night and day (Fig. 6). Particles with $\mathrm{D}_{a}<0.14 \mu \mathrm{m}$ (stage 1) were mainly made of carbonaceous species. The contribution of carbonaceous components decreased for stages 2 and 3, and increased again for stages 4 and 5. This was mainly due to variations in the NSWOM contribution, since the one of 

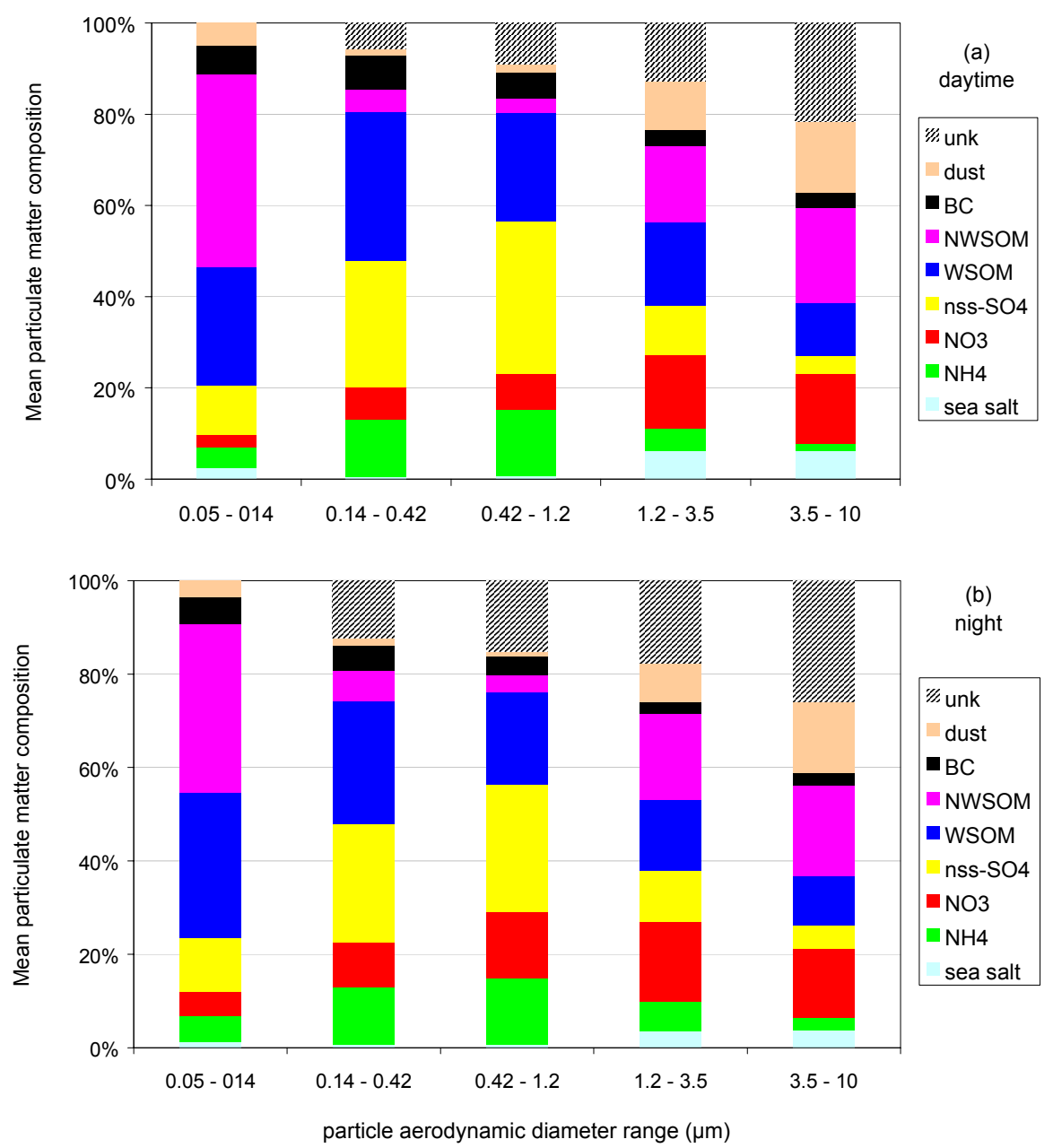

Fig. 6. Mean size-segregated aerosol chemical composition during (a) daytime and (b) nighttime at MTC during the Minatroc campaign, out of the Saharan dust advection period.

WSOM was quite similar in each size fraction (22 $\pm 7 \%$ ). $\mathrm{NssSO}_{4}^{2-}$ and $\mathrm{NH}_{4}^{+}$were mainly found into sub- $\mu \mathrm{m}$ particles, whereas $\mathrm{NO}_{3}^{-}$was more equally distributed over the 5 size fractions. Sea-salt and dust were almost exclusively present in the super- $\mu \mathrm{m}$ aerosol fraction. The air masses reaching MTC over the impactor nighttime sampling periods (21:00-9:00 UTC) were classified into 5 categories (W-Europe, NW-Europe, E-Europe, Mediterranean) based on 3-D back trajectories calculated by Balkanski et al. (2003) and observation of super- $\mu \mathrm{m}$ particle number (indicating the Saharan dust outbreak). The sub- and super- $\mu \mathrm{m}$ aerosol chemical compositions determined from nighttime impactor samples corresponding to air masses of clearly identified origins are indicated in Tables 4 and 5 and presented in Fig. 7. It should be noted that the variability in the composition of both size fractions is high, even in air masses from the same origin. However, some peculiarities in sub- $\mu \mathrm{m}$ aerosol composition can be noticed, which are significant with respect to uncertainties in each component quantification (Ta- ble 4). The average contribution of $\mathrm{NO}_{3}^{-}$to the sub- $\mu \mathrm{m}$ aerosol mass concentration was $>20 \%$ for 3 among 5 samples collected in air masses from NW-Europe origin, which is much higher than what was observed in any other type of air mass. In contrast, sub- $\mu \mathrm{m}$ aerosol in air masses from E-Europe origin was for more than $50 \%$ made of carbonaceous matter, due to specially high contribution of NWSOM and $\mathrm{BC}$. The molar ratio $\mathrm{NH}_{4}^{+} /\left(\mathrm{NO}_{3}^{-}+2 \times \mathrm{nssSO}_{4}^{2-}\right)$ also suggests that sub- $\mu \mathrm{m}$ was acidic in air masses from E-Europe and Mediterranean origin only. In air masses from Mediterranean origin, $\mathrm{nssSO}_{4}^{2-}$ was on average the main single component, and could make up to $50 \%$ of the aerosol mass in some samples. Despite a large uncertainty, it appears that mineral dust was a major component of the sub- $\mu \mathrm{m}$ aerosol during the Saharan dust outbreak. However, no $\mathrm{Ca}^{2+}$ was observed in the sub- $\mu \mathrm{m}$ aerosol collected with the SJAC. The occurrence of mineral dust in the sub- $\mu \mathrm{m}$ aerosol fraction might therefore result form the bouncing of non-sticky particles into the impactor. The super- $\mu \mathrm{m}$ aerosol chemical 

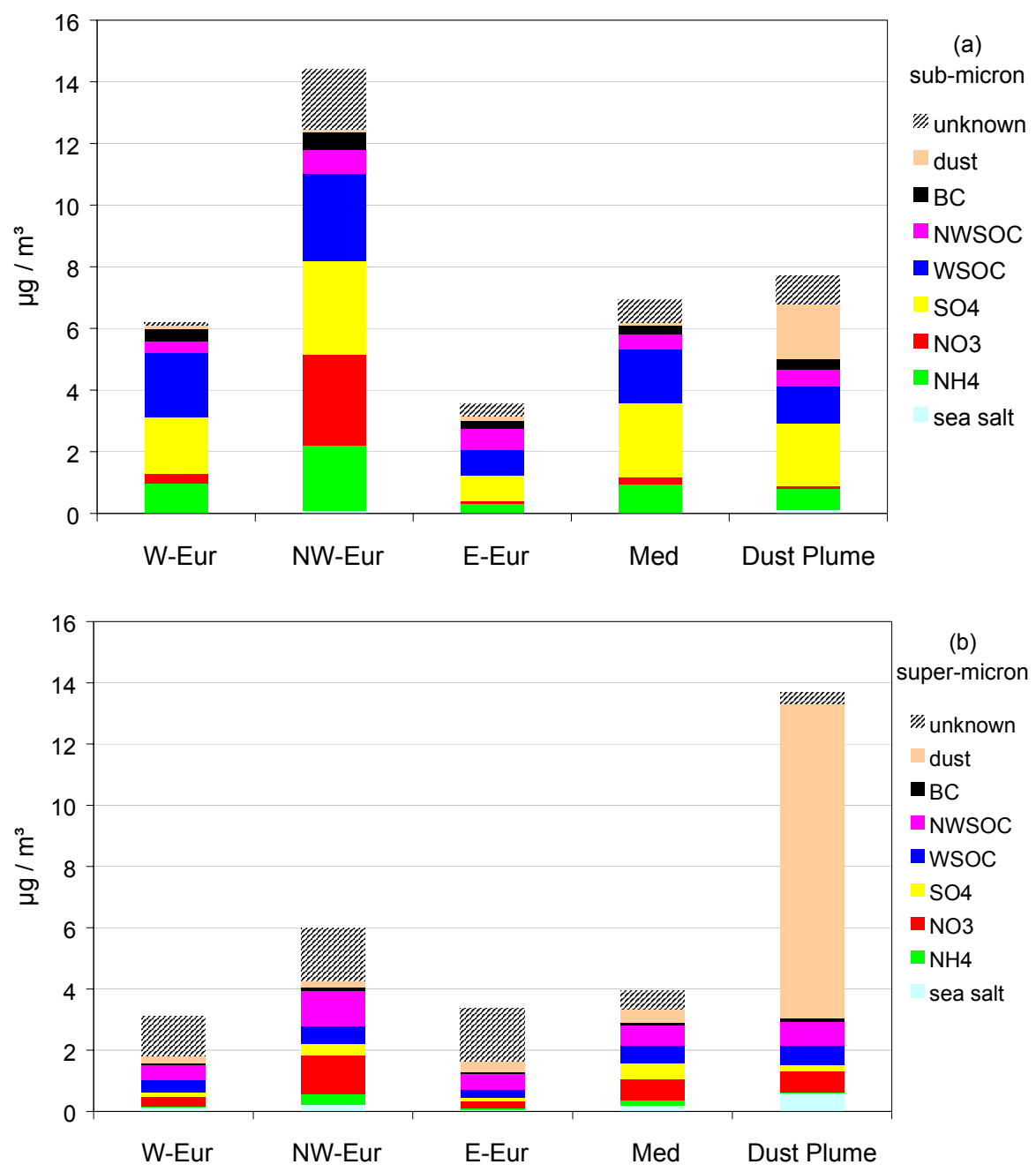

Fig. 7. Mean (a) sub- $\mu \mathrm{m}$ and (b) super- $\mu \mathrm{m}$ aerosol component concentrations in air masses from various origins during the Minatroc campaign.

composition is presented is Table 5. It should be kept in mind that chemical closure was not reached for the super$\mu \mathrm{m}$ fraction, which indicates that overall uncertainties were larger than estimated. The super- $\mu \mathrm{m}$ aerosol was characterized by a rather constant contribution of sea-salt with regard to uncertainties. The large contribution of $\mathrm{NO}_{3}^{-} \mathrm{ob}-$ served for air masses with NW-European origin $(20 \pm 6 \%)$ and Mediterranean origin (15\%) were not significantly different from others with respect to uncertainties. The contribution of mineral dust to the super- $\mu \mathrm{m}$ aerosol mass concentration was the highest during the Saharan dust outbreak. During this event, the $\mathrm{nssSO}_{4}^{2-} / \mathrm{nssCa}^{2+}$ ratio observed at MTC in the super- $\mu \mathrm{m}$ aerosol averaged $0.4 \pm 0.1$. Alpine glacier ice-cores (Schwikowski et al., 1999) and IC analyses of Saharan sand fine grain samples suggest that the $\mathrm{SO}_{4}^{2-} / \mathrm{Ca}^{2+}$ mass ratio should be about $0.4-0.6$ in pure Saharan dust. This shows that super- $\mu \mathrm{m} \mathrm{nssSO}{ }_{4}^{2-}$ was probably of pure Saharan origin during the dust outbreak. In contrast, large amounts of excess- $\mathrm{SO}_{4}^{2-}$ were still present in the sub- $\mu \mathrm{m}$ fraction. It can therefore be stated that coarse particles from Saharan and fine particles from anthropogenic origin were certainly externally mixed during the Saharan dust outbreak, and that no significant oxidation of $\mathrm{SO}_{2}$ onto mineral dust particles occurred in the Saharan dust plume. On the other hand, $\mathrm{NO}_{3}^{-}$ was predominantly in the coarse fraction (coarseNO $\mathrm{N}_{3}^{-} /$total $\mathrm{NO}_{3}^{-}=88 \pm 1 \%$ ). This value is not significantly higher than the value observed in air masses from Mediterranean and E-Europe origin, in which a large contribution of dust to the super- $\mu \mathrm{m}$ aerosol mass was also observed, but significantly higher that in air masses from $\mathrm{W}$-and $\mathrm{NW}$-Europe origin (coarseNO $\mathrm{N}_{3}^{-} /$total $\left.\mathrm{NO}_{3}^{-}=47 \pm 23 \%\right)$. This suggests that in presence of coarse dust particles, $\mathrm{NO}_{3}^{-}$shifts to the aerosol super- $\mu \mathrm{m}$ fraction due to the adsorption of $\mathrm{HNO}_{3}$ onto dust particles, leading to the displacement to the right of the equilibrium:

$\mathrm{NH}_{4} \mathrm{NO}_{3} \leftrightarrow \mathrm{HNO}_{3}+\mathrm{NH}_{3}$ 


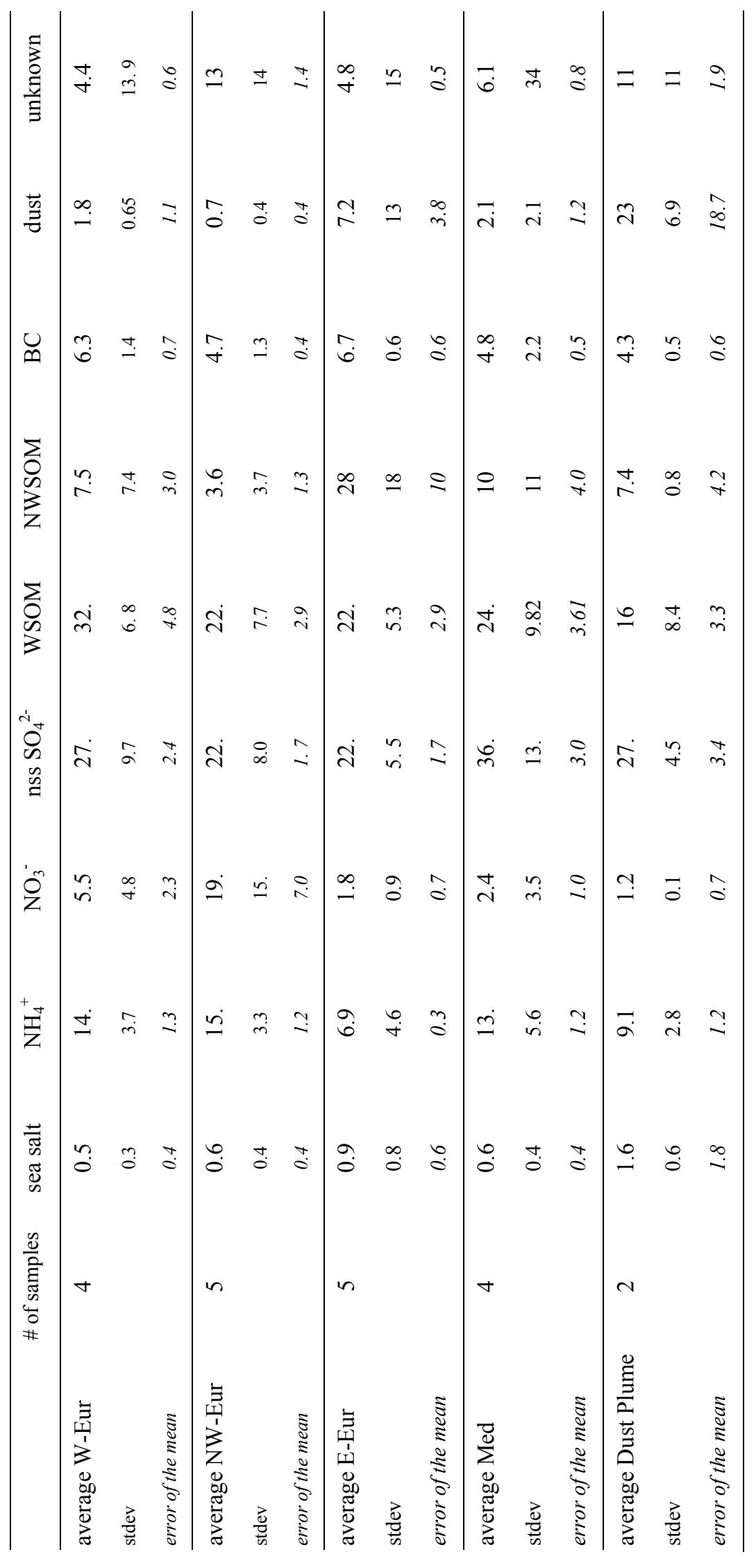




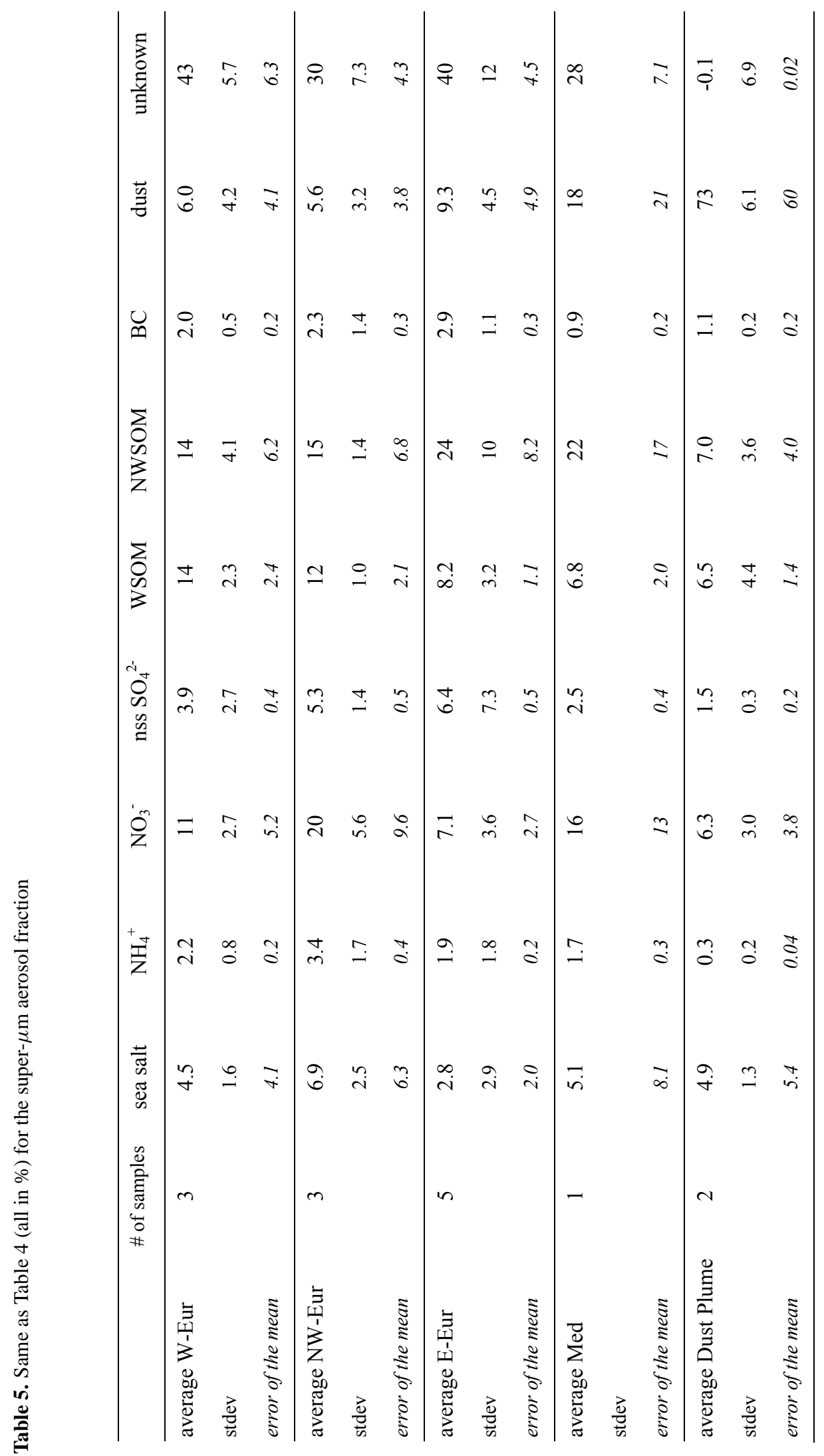




\section{Conclusions}

For the Minatroc campaign at MTC, the mean random uncertainties in the determination of sub- and super- $\mu \mathrm{m}$ aerosol mass concentrations from gravimetric measurements $\left(\mathrm{m}_{G M}\right)$, chemical analyses $\left(\mathrm{m}_{C A}\right)$, and particle size distribution measurements $\left(\mathrm{m}_{S D}\right)$ ranged between \pm 14 and $\pm 29 \%$. The main sources of random uncertainties were blank variability for $\mathrm{m}_{G M}$ and $\mathrm{m}_{C A}$, and particle sizing for $\mathrm{m}_{S D}$. Additional possible systematic error affecting mainly the conversion factors used to determine WSOM and NWSOM concentrations cannot be estimated. The comparison of $\mathrm{m}_{C A}$ with $\mathrm{m}_{G M}$ and $\mathrm{m}_{S D}$ shows that average differences were within experimental uncertainties for the sub- $\mu \mathrm{m}$ aerosol fraction. This indicates that within experimental uncertainties, the sub- $\mu \mathrm{m}$ aerosol was made of the ionic, carbonaceous and refractory components we quantified. In contrast, mass closure was not obtained for the aerosol super- $\mu \mathrm{m}$ fraction. This shows that the sources of random and/or systematic errors associated with the determination of $\mathrm{m}_{C A}, \mathrm{~m}_{G M}$ and $\mathrm{m}_{S D}$ for the super$\mu \mathrm{m}$ aerosol fraction were not fully understood. Taking into account analytical uncertainties, we found significant differences in the sub- $\mu \mathrm{m}$ aerosol composition in air masses from different origins. The largest contribution of $\mathrm{NO}_{3}^{-}$was observed in air masses from NW-Europe origin, whereas more than $50 \%$ of the sub- $\mu \mathrm{m}$ aerosol mass was made of carbonaceous components in air masses from E-Europe origin. The difference in sub- and super- $\mu \mathrm{m}$ chemical composition during the Saharan dust outbreak suggests that Saharan dust and anthropogenic particles were externally mixed. No interaction between $\mathrm{SO}_{2}$ and dust could be detected from our measurements. In contrast, the displacement of $\mathrm{NO}_{3}^{-}$towards the aerosol super- $\mu \mathrm{m}$ fraction in presence of dust coarse particles indicates a significant interaction of $\mathrm{HNO}_{3}$ with dust particles. This suggests that the interaction of secondary aerosol precursors with pre-existing primary particles should be taken into account in secondary aerosol formation modeling.

Acknowledgements. This work was supported by the EC contract EVK2-CT-1999-00003 (MINATROC).

Edited by: Y. Balkanski

\section{References}

Balkanski, Y., Bauer, S., Dingenen, R., Bonasoni, P., Schulz, M., Fischer, H., Gobbi, G., Hanke, M., Hauglustaine, D., Putaud, J., Stohl, A., and Raes, F.: The Mt Cimone, Italy, free tropospheric campaign: principal characteristics of the gaseous and aerosol composition from European pollution, Mediterranean influences and during African dust events, Atmos. Chem. Phys. Discuss., 3, 1753-1776, 2003.

Bonasoni, P., Colombo, T., Lenaz, R., Giovanelli, G., Evangelisti, F., Ravegnani, F., Santaguida, R., and Tesi, G.: Effect of Saharan dust transport on ozone and carbon dioxide concentrations, in:
The impact of African dust across the Mediterranean, Envir. Sci. Technol Lib., Kluwer, 11, 313-322, 1996.

Bonasoni, P., Stohl, A., Cristofanelli, P., Calzolari, F., Colombo, T., and Evangelisti, F.: Background ozone variations at Mt. Cimone, Atmos. Environ., 34, 5183-5189, 2000.

Cachier, H., Bremond, M. P., and Buat-Ménard, P.: Determination of atmospheric soot carbon with a simple thermal method, Tellus 41B, 379-390, 1989.

Carson, P. G., Johnston, M. V., and Wexler, A. S.: Real time monitoring of the surface and total composition of atmospheric particles, Aeros. Sci. Technol., 26, 291-300, 1997.

Decesari, S., Facchini, M. C., Fuzzi, S., and Tagliavini, E.: Characterization of water-soluble organic compounds in atmospheric aerosol: A new approach, J. Geophys. Res., 105, 1481-1489, 2000.

Fuzzi, S., Decesari, S., Facchini, M. C., Matta, E., Mircea, M., and Tagliavini, E.: A simplified model of the water soluble organic component of atmospheric aerosol, Geophys. Res. Lett., 20, 4079-4082, 2001.

Ge, Z., Wexler, A. S., and Johnston, M. V.: Laser desorption/ionization of single ultrafine multicomponent aerosols, Environ. Sci. and Technol., 32, 3218-3223, 1998.

Gray, H. A., Cass, R. G., Huntzicker, J. J., Heyrdahl, E. K., and Rau, J. A.: Characteristics of atmospheric organic and elemental carbon particle concentrations in Los Angeles, Environ. Sci. Technol., 20, 580-589, 1986.

IPCC, Climate Change 2001: The scientific basis. Contribution of Working Group I to the third assessment report of the Intergovernmental Panel on Climate Change, edited by Houghton, J. T. Ding, Y., Griggs, D. J., Noguer, M., van der Linden, P. J., Dai, X., Maskell, K., and Johnson, C.A., Cambridge University Press, Cambridge, United Kingdom and New York, NY, USA, 881 pp, 2001.

Keuken, M. P., Schoonebeeek, C. A. M., van Wensveen-Louter, A., and Slanina, J.: Simultaneous sampling of $\mathrm{NH}_{3}, \mathrm{HNO}_{3}, \mathrm{HCl}$, $\mathrm{SO}_{2}$, and $\mathrm{H}_{2} \mathrm{O}_{2}$ in ambient air by wet annular denuder system, Atmos. Environ., 22, 2541-2548, 1988.

Khlystov, A., Wyers G. P., and Slanina, J.: The steam jet aerosol collector, Atmos. Environ., 29, 2229-2234, 1995.

Loo, B. W. and Cork, C. P.: Development of a high efficiency virtual impactor, Aerosol Sci. Technol., 9, 167-176, 1988.

Murphy, D. M., Thomson, D. S., and Mahoney, M. J.: In situ measurement of organics, meteoritic material and other elements in aerosol at 5 to $19 \mathrm{~km}$, Science, 282, 1664-1669, 1998.

Putaud, J. P., Van Dingenen, R., Mangoni, M., Virkkula, A., Raes, F., Maring, H., Prospero, J. M., Swietlicki, E., Berg, O. H., Hillamo, R., and Mäkelä, T.: Chemical mass closure and assessment of the origin of the submicron aerosol in the marine boundary layer and the free troposphere at Tenerife during ACE2, Tellus 52B, 141-168, 2000.

Schwikowski, M., Döscher, A., Gäggeler, H. W., and Schotterer, U.: Anthropogenic versus natural sources of atmospheric sulphate from an Alpine ice core, Tellus. 51B, 938-951, 1999.

Virkkula, A., Van Dingenen, R., Raes, F., and Hjorth, J.: Hygroscopic properties of aerosol formed by oxidation of limonene, $\alpha$ pinene and $\beta$-pinene, J. Geophys. Res., 104, 3569-3579, 1999. 